\title{
Efektivitas Kemampuan Kerja terhadap Semangat Kerja pada PT. Doosan Jaya Sukabumi
}

\section{Resta Restiani1 ${ }^{*}$, Faizal Mulia², Dicky Jhoansyah ${ }^{3}$}

1,2,3 Universitas Muhammadiyah, Sukabumi - Indonesia

\author{
A R T I C L E I N F O \\ Article history: \\ Received 23 April 2020 \\ Received in revised form \\ 13 May 2020 \\ Accepted 5 June 2020 \\ Available online 29 June \\ 2020 \\ Kata Kunci: \\ Kemampuan kerja; \\ Semangat Kerja \\ Keywords: \\ Work Ability, Spirit at Work
}

\begin{abstract}
A B S T R A K
Perkembangan pada perusahaan PT Doosan Jaya Sukabumi mengalami penurunan dalam kemampuan kerja maupun semangat kerja yakni dalam kemampuan kerja tidak semua karyawan mempunyai skill dan sebaliknya semua karyawan tidak semua memiliki semangat kerja yang besar. Sehingga pada riset ini memiliki tujuan untuk memahami serta mengetahui pengaruh kemampuan kerja terhadap semangat kerja. Dalam riset ini untuk mengolah data maka peneliti menggunakan metode kuantitatif dengan pendeketan asosiatif, serta peneliti menyebarkan kuesioner 100 responden kepada karyawan PT. Doosan Jaya Sukabumi untuk menghasilkan data terhadap perusahaan tersebut. Hasil uji T kemampuan kerja menunjukkan bahwa thitung pada penelitian ini adalah 9.280 dengan nilai signifikan 0,000, maka nilai signifikan 0,000 <dibandingkan dengan 0,05, dapat disimpulkan bahwa variabel kemampuan kerja berpengaruh positif terhadap semangat kerja. di PT. Doosan Jaya Sukabumi.
\end{abstract}

A B S T R A C T

The development of the company PT Doosan Jaya Sukabumi increases the decrease in work ability or increase work in work ability not all employees need skills and conversely all employees do not all have great morale. Because this research has goals to be achieved as well. In this study to process data, the researchers used quantitative methods with associative approach, and researchers tested 100 respondents for the employees of PT. Doosan Jaya Sukabumi to produce data on the company. T-test results show the ability of work in this study was 9,280 with a significant value of 0,000 , then a significant value of $0,000<$ compared to 0.05 , it can be concluded that the variable work ability increased positively on morale. at PT. Doosan Jaya Sukabumi.

\footnotetext{
* Corresponding author.

E-mail : restarestiani@ummi.ac.id (Resta Restiani)
} 


\section{Pendahuluan}

Perkembangan industri garmen atau pakaian jadi di Indonesia menunjukkan kearah yang sangat relatif seperti menurut (Indonesia, 2019) pada kesimpulan tahun 2019 selama 3 bulan, dalam masa pertumbuhan industri garmen tercatat angka paling besar yaitu 18,98\%. Jumlah ini naik pada periode tahun lalu 2018 sebesar 8,73\%. Dari peningkatan pertumbuhan ini membuktikan bahwa industri garmen telah memperlihatkan perkembangannya kearah yang lebih maju dari masa lampau. Perseroan yang terletak disukabumi ialah PT Doosan Jaya Sukabumi yang memproduksi pakaian jadi untuk kaum wanita dan perusahaan tersebut termasuk industri garmen. Demi tercapainya sebuah keberhasilan perusahaan membutuhkan kapasitas yang baik dan terarah dengan jelas karena dalam pencapaian tujuan sebuah perusahaan ialah yang sangat penting dan bisa dikatakan perusahaan itu berhasil, Sehingga dalam sebuah perusahaan harus lebih memperhatikan dalam segala pengadaan semua pegawai yakni untuk lebih memenuhi perangkuhan serta serius merealisasikannya. Sehingga dalam sebuah perusahaan sumber daya manusia ialah " segala sesuatu kegiatan yang sangat bermutu karena pelaku dari kegiatan sekelompok orang tersebut, sehingga kualitas sumber daya manusia harus lebih dikembangkan dan diarahkan supaya tercapainya tujuan yang diharapkan", (NA'IM, 2017). Pertumbuhan dalam memperoleh perseroan akan lebih penting jikalau perusahaan tersebut mempunyai medium yang sangat bermakna Tentunya setiap perusahaan pasti menginginkan semua karyawan nya mempunyai semangat kerja yang sangat besar agar semua target industri berhasil, karena semangat kerja suatu sarana yang paling pokok teruntuk pegawai maupun perseroan tersebut, sehingga semangat kerja salah satu keseriusan seseorang yang berkualitas dengan melaksanakan suatu aktivitas dan memotivasi demi mendapatkan hasil optimal dan jika seorang pegawai memiliki antusiasme yang baik tentunya hendak memberikan perilaku yang baik dan akan saling menguntungkan satu sama lain.

Dalam sebuah perusahaan pasti harus mempunyai kemampuan yang tepat dalam menjalankan pekerjaan nya, jika seorang karyawan mempunyai kemampuan maka akan lebih nyaman dalam menjalankan pekerjaan nya itu , karena Keahlian situasi yang terdapat dalam perseorangan karyawan nya itu sendiri dan akan melakukan pekerjaannya secara bersungguh- sungguh dan akan berhasil dalam melaksanakan pekerjaan nya sesuai bidang pekerjaannya tersebut. sehingga akan tercapainya pekerjaan yang sudah ditetapkan sebanding atas tujuan yang telah disesuaikan dengan arahan perusahaan tersebut. Berdasarkan hasil wawancara saya dengan beberapa karyawan PT. Doosan Jaya kabupaten Sukabumi Para karyawan dalam menjalankan pekerjaan nya tidak memiliki semangat kerja yang tinggi dan baik, yang disebabkan oleh kurang nya kerjasama antar karyawan sehingga dalam melakukan pekerjaan nyapun masih saling mengandalkan satu sama lain, sehingga pencapaian target nya pun tidak terpenuhi dengan baik.

Berdasarkan permasalahan tersebut maka peneliti tertarik untuk melaksanakan sebuah observasi yang berjudul "Efektivitas Kemampuan Kerja Terhadap Semangat Kerja Pada PT Doosan Jaya Sukabumi". Dengan memiliki tujuan observasi yaitu untuk mengetahui serta memahami pengaruh efektivitas kemampuan kerja terhadap semangat kerja pada PT. Doosan Jaya Sukabumi. Untuk mengetahui lebih rinci mengenai variabel Kemampuan kerja dan semangat kerja pada PT. Doosan Jaya Sukabumi dapat dijelaskan sebagai berikut:

\section{Manajemen sumber daya manusia}

Dalam perusahaan sumber daya manusia peran yang sungguh-sungguh berarti untuk semua industri karena kepandaian seorang pegawai sangat lah penting dalam hal apapun. MSDM yakni "eksploitasi individu dengan menggunakan suatu kesibukan seperti perancangan, dan penanganan yang menjadikan salah satu kekuasaan untuk memperoleh keinginan Bersama" (sedarmayanti, 2017). Menurut Armstrong (2016) (dalam Fadhil \& Ashoer, 2020) sumber daya manusia yakni "kebijakan menjadi seakan-akan di perhitungkan ketika pengutipan sebuah keputusan".

\section{Kemampuan Kerja}

Kemampuan kerja suatu tahapan dalam sebuah perusahaan untuk menguji seorang pegawai dalam melakukan pekerjaan yang diperintahkan oleh pihak perusahaan agar bisa menjalankan sebuah pekerjaan dengan keseriusan, supaya menghasilkan sasaran untuk mencapai kesuksesan sehingga kemampuan yakni sarana yang sudah melekat pada diri seorang pegawai yang tanpa harus dipaksa dalam bentuk apapun. Jika seorang pegawai yang mempunyai kemampuan kerja maka akan meningkatkan pengetahuannya dalam mengembangkan pekerjaannya maupun perusahaan. Selain itu keistimewaan seorang karyawan yakni menguasai semua keterampilan dan sanggup menjalankan nya tanpa ada keluh kesah yang dirasakan nya serta pekerjaan tersebut akan dijadikannya hobi. Kemampuan kerja ialah peran yang sangat penting pada diri sendiri maupun perusahaan, karena kemampuan karyawan "suatu potensi yang harus dimiliki karyawan untuk menyelesaikan pekerjaan nya tersebut", menurut Robbins (2014) (dalam Mailisa, Hendri, \& Fauzan, 2016).

Dalam diri seorang karyawan Kemampuan kerja suatu hal yang sangat penting karena untuk bisa membantu kita dalam menjalankan apapun contohnya seperti dalam sebuah perusahaan jika kita mempunyai 
kemampuan yang tinggi dan baik maka akan lebih di butuhkan dalam situasi apapun dan hal tersebut akan saling menguntungkan bagi karyawan maupun perusahaan. Kemampuan kerja menurut Thoha (2011) (dalam Eva Mufidah, 2019)yakni " elemen pada kedewasaan yang bersangkutan dengan pemahaman beserta keahlian yang mampu terdapat pada pembelajaran, pelatihan serta kemahiran".

Karena kemampuan perlu ditempatkan searah dengan kemahiran yang dimiliki dalam pegawai supaya menghasilkan yang terbaik, menurut Wibowo (2013:93) (dalam Fristia \& Sunuharyo, 2019) mengatakan bahwa " ability menyatakan bahwa kualitas perseorangan untuk menerbitkakn beragam tugas dalam bekerja", hal ini menafsirkan bahwa dalam melakukan sebuah pekerjaan sangat dibutuhkan kemampuan supaya dapat didukunng dan melaksanakan pekerjaan yang semestinya sehingga dapat menghasilkan sebuah hasil yang sangat baik.

Dalam sebuah perusahaan pasti mempunyai macam-macam kemampuan kerja yang sudah ditentukan, seperti yang di katakan menurut Robbins dan Judge (2012:57) menjelaskan (Jatiningrum, Musadieq, \& Prasetya, 2016) mengatakan bahwa ada 2 macam dalam kemampuan kerja diantaranya yakni : a). kemampuan intelektual yang artinya suatu peran kemampuan yang sangat diperlukan dalam melakukan aktivitas berpikir, mental maupun dalam memecahkan sebuah permasalahan yang sedang terjadi dalam sebuah perusahaan, b) Kemampuan fisik maknanya yaitu kemampuan dalam melakukan tugas-tugas yang memperjuangkan tenaga maupun skill. Kemampuan intelektual maupun fisik yakni yang sangat dibutuhkan dalam sebuah pekerjaan, karena dalam melakukan sebuah pekerjaan harus sesuai pada persyaratan kemampuan pekerjaan tersebut, jika tidak ada kemampuan dalam melakukan pekerjaan tidak akan terlalu maksimal.

Berdasarkan Dimensi kemampuan kerja Menurut Moenir (dalam Moch Riza Afgani, 2017) yaitu sebagai berikut : pengetahuan (knowledge), keterampilan (skill), dan pengalaman.

\section{Semangat kerja}

Menurut Badriyah (2015) (dalam Nasution, 2019) semangat kerja "salah satu kondisi seseorang dalam melaksanakan pekerjaan dengan lebih cepat dan baik dalam sebuah perusahaan, sehingga akan menunjukkan sejauh mana karyawan dalam melakukan pekerjaan nya". semangat kerja hal yang terpenting dalam diri seorang karyawan jika seorang pegawai yang memiliki semangat yang besar dan baik hendak memberikan pandangan yang positif dan dalam melaksanakan pekerjaan nya pun akan penuh dengan rasa semangat dan senang. Semangat kerja yakni yang sangat dibutuhkan saat semua aktivitas kegiatan tanpa adanya semangat kerja kesuksesan pada perusahaan tidak akan teraih serta semangat kerja tidak akan selamanya terselip dalam diri seseorang. Dalam semangat kerja yang sangat berarti seperti suasana dalam lingkungan pekerjaan maupun penghasilan yang diterima.

Suksesnya dalam sebuah perusahaan bisa dilihat dari adanya semangat kerja yang besar dan bertanggung jawab bagi pekerjaannya sehingga akan membawa dampak yang baik serta mampu mengatasi kesulitan mengenai pekerjaannya sehingga akan tercapainya tujuan perusahaan (Dadang Aris Subiantoro, Woro Utari, 2019). Semangat kerja yaitu "suatu peran yang sangat dibutuhkan dalam keberhasilan suatu perusahaan sehingga atasan agar mampu memberikan semangat kepada para karyawannya tersebut" menurut (Purwanto 2012 :83) (dalam Radot Rosana Devika.RG, 2019) dan semangat kerja ataupun moril kerja mengungkapkan bahwa "keceriaan pada seorang pegawai untuk melakukan sebuah pekerjaan yang diberikan, sehingga pekerjaan dapat terselesaikan dengan tepat waktu" menurut Sastrohadiwiryo dalam Yusmiaty (2013) (dalam Sugara, Adji, \& Chamidah, 2020). Dengan terwujudnya semangat kerja yang sesuai maka akan menghasilkan kemauan bagi seorang karyawan dalam melakukan pekerjaan lebih bermakna, dan dalam perusahaan memiliki nilai yang mempengaruhi semangat kerja seperti yang dikatakan Menurut Handayani (2016) (dalam Livia Putri Kusuma, 2018) yakni : a) Presensi suatu eksistensi pegawai yang bertepatan dengan tugas serta kewajibannya, b) Kerjasama salah satu peran yang menandakan persetujuan antara dua orang atau lebih, serta Kerjasama dapat menunjukkan dampak positif apabila dilakukan dengan baik, c) kepuasan kerja situasi emosional pegawai yang akan terjadi maupun tidak terjadi dalam lingkungan pekerjaan, d) serta kedisiplinan sikap ataupun tingkah laku yang taat terhadap peraturan perusahaan ataupun organisasi yang sudah ditentukan.

Adapun dimensi semangat kerja menurut (Muliadi, 2019) adalah Disiplin kerja dalam sebuah perusahaan,Tanggung jawab atas pekerjaannya, Kerjasama dalam melakukan pekerjaan, dan Kepuasan kerja.

Berikut ini untuk menjelaskan lebih rinci mengenai variabel kemampuan kerja terhadap semangat kerja dalam penelitian berikut ini gambar kerangka pemikiran yaitu sebagai berikut : 


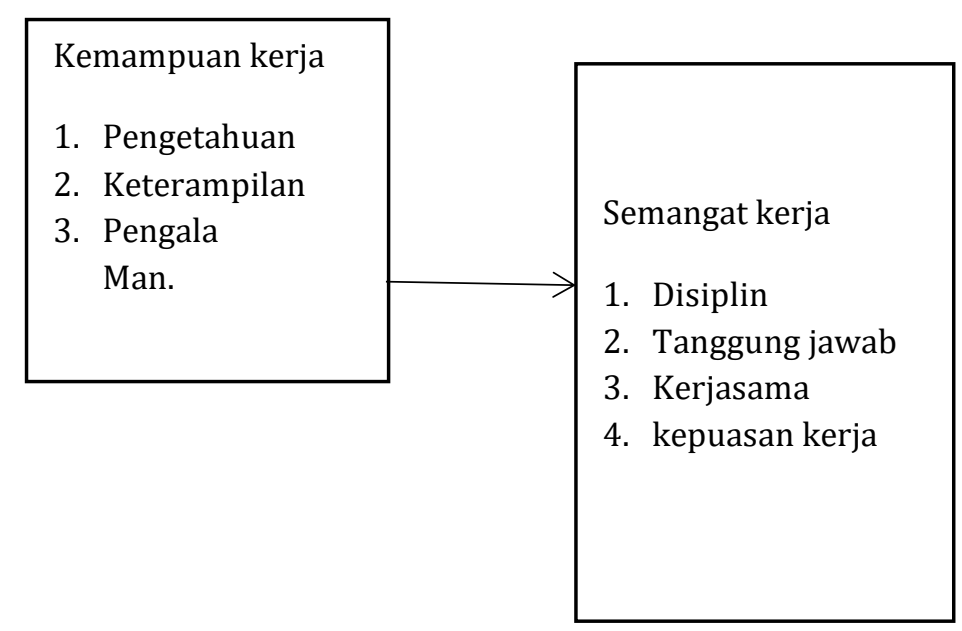

Gambar 1. Paradigma penelitian

Sumber: Hasil Garapan penelitian, 2020

\section{Metode}

Metode penelitian pada observasi yang dilakukan peneliti yakni kuantitatif dengan metode asosiatif yang menggambarkan analisis dalam memecahkan suatu persoalan dengan menggunakan bantuan penggarapan statistik yakni menguasai asosiasi antara objek penelitian yang sedang diobservasi. Dalam pengerjaan menggunakan software IBM SPSS Statistic Version 24. Dengan metode akumulasi yang digunakan dalam riset ini yakni observasi dan penyebaran pertanyaan kepada pegawai perusahaan untuk mendapatkan jumlah data terkhusus yang berkaitan dengan riset tersebut.

Pada penjajakan ini populasi yang ditetapkan oleh peneliti yaitu karyawan PT Doosan jaya kabupaten sukabumi, maka sampel yang digunakan dalam penjajakan ini yakni mengaplikasikan jenis simple random sampling yang termasuk kedalam probability sampling dengan mengajukan pertanyaan kepada pegawai sebanyak 100 PT. Doosan Jaya Sukabumi, dan untuk menghasilkan data yang lebih akurat peneliti menggunakan Teknik Analisa uji validitas dan uji reliabilitas. Serta Teknik analisis data yang digunakan dalam penelitian ini adalah uji normalitas, koefisien korelasi, koefisien determinasi, regresi linear sederhana dan uji secara parsial.

\section{Hasil dan pembahasan}

Adapun hasil perolehan kuisioner dari 100 responden yakni karyawan PT Doosan Jaya Sukabumi, yang diolah dengan mengenakan software IBM SPSS Statistic version 24 didapatkan hasil yang cocok dengan objek penelitian. Berikut hasil serta pembahasan yang dapat diuraikan pada tabel dibawah ini.

Tabel 1.Hasil perolehan Perhitungan Uji Validitas

\begin{tabular}{cccc}
\hline Variabel & Skor $\mathbf{R}_{\text {hitung }}$ & Skor $\mathbf{R}_{\text {tabel }}$ & Status \\
\hline & 0.710 & 0.195 & Data sesuai dan \\
diterima & \\
& 0.601 & 0.195 & 0.195 \\
\\
& 0.586 & 0.195 & Data sesuai dan \\
& 0.633 & 0.195 & diterima \\
\end{tabular}


Sumber: Hasil garapan penelitian, 2020

Menurut data tabel diatas, dapat dipahami bahwa nilai korelasi antara skor item vairabel X dan Y seluruh item pada hasil pengujian tersebut mempunyai jumlah skor di atas 0,195 sehingga seluruh butir instrument kemampuan kerja $(\mathrm{X})$ dan semangat kerja $(\mathrm{Y})$ dinyatakan valid, karena keseluruhan memiliki jumlah skor $\mathrm{R}_{\text {hitung }}>\mathrm{Rt}_{\text {abel. }}$.

Tabel 2. Perolehan Perhitungan Reliabilitas Kemampuan kerja

\begin{tabular}{cccc}
\hline Cronbach's Alpha & \multicolumn{2}{c}{$\begin{array}{c}\text { Cronbach's Alpha Based } \\
\text { on Standardized Items }\end{array}$} & N of Items \\
\hline &, 645 &, 647 & 5 \\
\hline
\end{tabular}

Sumber : Hasil penelitian, 2020

Berdasarkan hasil uji reabilitas yang dipaparkan pada variabel X yaitu kemampuan kerja mengahasilkan data 0,647 >0.6, maka kuesioner variabel X 0,647 >0,6 sehingga bisa dijadikan faktual atau reliabel.

Tabel 3. Perolehan Hasil perhitungan Uji Reliabilitas Y

\begin{tabular}{ccc}
\hline & $\begin{array}{c}\text { Cronbach's } \\
\text { Alpha Based on } \\
\text { Cronbach's Alpha }\end{array}$ & Standardized Items \\
\hline, 649 &, 650 & N of Items \\
\hline
\end{tabular}

Sumber : Hasil penelitian, 2020

Hasil uji realibilitas pada variabel Y yaitu semangat kerja menghasilkan $0,650>0.6$, lalu kuesioner semangat kerja Y $0.650>0,6$ sehingga dapat dikatakan reliabel sehingga layak menjadi alat ukur untuk Teknik analisi data selanjutnya.

Data yang telah diolah oleh peneliti diatas menunjukkan bahwa nilai sig. dari Kolmogorov smirnov test menunjukkan hasil sebesar ,200 > 0,05 dan dengan itu bisa dikatakan model penelitian berdistribusi normal.

Tabel 4. Perolehan perhitungan Hasil Uji Normalitas

\begin{tabular}{llr}
\hline & & Unstandardized Residual \\
\hline $\mathrm{N}$ Normal Parameters ${ }^{\mathrm{a}, \mathrm{b}}$ & & 100 \\
& Mean &, 0000000 \\
& Std. & 19,37450374 \\
Most Extreme Differences & Deviation &, 055 \\
& Absolute &, 053 \\
& Positive &,- 055 \\
Test Statistic & Negative &, 055 \\
Asymp. Sig. (2-tailed) & &, $200^{\text {c,d }}$ \\
\hline
\end{tabular}

Sumber: Hasil garapan peneliti, 2020

Tabel 5. Perolehan perhitungan Koefisien Korelasi

\begin{tabular}{cccc}
\hline & $\mathrm{X}$ & $\mathrm{Y}$ \\
\hline $\mathrm{X}$ & Pearson & 1 &, $684^{* *}$ \\
& Correlation & & \\
Sig. (2- & &, 000 \\
tailed) & 100 & 100 \\
$\mathrm{~N}$ & & \\
\hline
\end{tabular}




\begin{tabular}{ccc}
\hline $\mathrm{Y}$ & $\begin{array}{c}\text { Pearson } \\
\text { Correlation } \\
\text { Sig. }(2-\end{array}$ &, $684^{* *}$ \\
tailed) &, 000 & 1 \\
$\mathrm{~N}$ & 100 & 100 \\
\hline
\end{tabular}

**. Correlation is significant at the 0.01 level (2-tailed).

Sumber: Hasil Penelitian, 2020

Perolehan data dari koefisien korelasi diatas memperoleh bahwa korelasi variabel X dan Y sebesar 0.684, hingga berhasil dikatakan adanya relasi diantara variabel kemampuan kerja terhadap semangat kerja.

Tabel 6. Perolehan perhitungan Koefisien Determinasi

\begin{tabular}{lllll}
\hline Model & $\mathrm{R}$ & $\mathrm{R}$ Square & $\begin{array}{l}\text { Adjusted } \\
\text { Square }\end{array}$ & $\mathrm{R}$ \\
\hline 1 &, $684^{\mathrm{a}}$ &, 468 &, 462 & 2,62941 \\
\hline
\end{tabular}

a. Predictors: (Constant), $x$

Sumber: Hasil Penelitian, 2020

Berdasarkan hasil perhitungan diatas menyatakan jumlah Rsquare sebesar 0,468 ataupun dalam bentuk persentase sebesar $46,8 \%$, maka memperoleh variabel X mempunyai pengaruh sebesar $46,8 \%$ dan $53,2 \%$ dipengaruhi oleh berbagai faktor ataupun variabel lainnya yang berada diluar penelitian ini.

Berdasarkan hasil penyebaran kuesioner yang telah diolah dengan menggunakan SPSS, maka dapat dihasilkan analisis regresi linear yaitu dengan menghasilkan nilai bobot konstanta (a) sejumlah 0,5851 serta (b) sejumlah 0,691 ataupun yang dapat dirumuskan persamaan regresi yakni $Y=0,5851+0,691 \mathrm{X}$.

Tabel 7. Perolehan Hasil Regresi Linear Coefficients ${ }^{\mathrm{a}}$

\begin{tabular}{|c|c|c|c|c|c|c|c|}
\hline \multirow{4}{*}{$\begin{array}{l}\text { Model } \\
1\end{array}$} & \multirow[b]{3}{*}{ (Constant) } & \multicolumn{2}{|c|}{$\begin{array}{l}\text { Unstandardized } \\
\text { Coefficients }\end{array}$} & \multirow[t]{2}{*}{ 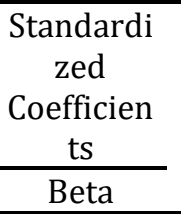 } & \multirow[b]{2}{*}{$\mathrm{T}$} & \multirow[b]{2}{*}{ Sig. } & \\
\hline & & $\mathrm{B}$ & Std. Error & & & & \\
\hline & & 5,851 & 1,336 & & $\begin{array}{r}4,37 \\
9\end{array}$ & & ,000 \\
\hline & $\mathrm{X}$ & 691 & 074 & 684 & $\begin{array}{r}9,28 \\
0\end{array}$ & & , 000 \\
\hline
\end{tabular}

Sumber: Hasil Penelitian, 2020

Maka persamaan tersebut dapat disimpulkan sebagai berikut:

Konstanta sebanyak 0,5851 tercantum maka koefisien variabel kemampuan kerja sejumlah 0,5851, Sedangkan regresi $Y$ sejumlah 0,691 mengutarakan hingga setiap akumulasi 1\% nilai kemampuan kerja bahwa arti semangat kerja meningkat sebesar 0,691 Koefisien regresi terkandung produktif positif hingga dapat diartikan yakni terdapat adanya pengaruh kemampuan kerja kepada semangat kerja yakni positif.

Parsial (Uji T) mempunyai tujuan untuk memahami banyaknya pengaruh terhadap masing-masing variabel independent secara individual terhadap dependen (Sunyoto, 2011) (Budi yanti, Hasna Afriani, 2019). Adapun hasil Uji t yang dilakukan pada variabel sebagai berikut :

Tabel 8. Perolehan hasil Uji T (Parsial) 


\begin{tabular}{|c|c|c|c|c|c|c|}
\hline \multirow{4}{*}{$\begin{array}{l}\text { Model } \\
1\end{array}$} & & Unstandardize & Coefficients & $\begin{array}{c}\text { Standardized } \\
\text { Coefficients }\end{array}$ & \multirow[b]{2}{*}{$\mathrm{T}$} & \multirow[b]{2}{*}{ Sig. } \\
\hline & & B & Std. Error & Beta & & \\
\hline & (Constant) & 5,851 & 1,336 & & 4,379 & 000 \\
\hline & $\mathrm{X}$ & 691 &, 074 & 684 & 9,280 & ,000 \\
\hline
\end{tabular}

Sumber : Hasil Garapan peneliti, 2020

Hasil Garapan diatas menunjukkan bahwa skor thitung dari kemampuan kerja sejumlah 9,280 pada tingkatan bermakna 0.000 . Nilai signifikan $0.0000<$ dari 0,05 dengan koefisien regresi memiliki angka positif dengan jumlah 9,280 maka dengan itu dapat diartikan variabel X berpengaruh terhadap semangat kerja.

\section{Simpulan dan saran}

Diperoleh pada data hasil dari koefisien determinasi menunjukkan bahwa adanya pengaruh kemampuan kerja berpengaruh signifikan serta positif terhadap semangat kerja sebesar $46,8 \%$, dan dari setiap variabel $(X)$ dan $(Y)$ pada garapan ini mampu memperoleh melalui faktornya, sehingga bisa digunakan jadi penunjuk yang diperoleh untuk peneliti yang akan mendatang.

Hasil kesimpulan diatas maka PT Doosan Jaya Sukabumi harus lebih memperhatikan kerjasama antar pegawai, supaya dalam hal kerjasama harus lebih ditingkatkan lagi supaya lebih baik dari sebelumnya.

\section{Daftar Rujukan}

Budi yanti, Hasna Afriani, F. (2019). Pengaruh Kemampuan Kerja dan Motivasi Kerja terhadap Prestasi Kerja (Studi pada Karyawan PT Wahana Wirawan Riau) Budi. Jurnal Manajemen Dan Kewirausahaan, 10(1), 49-61. Retrieved from http://jurnalmanajemen.petra.ac.id/index.php/man/article/view/16635/16627

Dadang Aris Subiantoro, Woro Utari, S. H. (2019). Analisis semangat kerja, lingkungan kerja dan motivasi kerja terhadap prestasi kerja pegawai sekertariat daerah kabupaten bojonegoro Dadang. Jurnal Mitra Manajemen (JMM Online), 3(4), 424-437. Retrieved from http://ejurnalmitramanajemen.com/index.php/jmm/article/view/125/69

Eva Mufidah, R. F. (2019). Pengaruh motivasi kerja dan kemampuan kerja terhadap kinerja umkm di kota pasuruan ( studi pada UMKm tahun 2018). JRE: Jurnal Riset Entrepreneurship, 2(2), 29-36.

Fadhil, M., \& Ashoer, M. (2020). Pengaruh Budaya Kerja, Kemampuan dan Komitmen terhadap Kinerja Dosen pada Perguruan Tinggi di Kabupaten Maros. JIMF (Jurnal Ilmiah Manajemen Forkamma), 3(2), 161-169.

Fristia, M. A., \& Sunuharyo, B. S. (2019). Pengaruh Kemampuan Kerja dan Motivasi Kerja Terhadap Kinerja Karyawan (Studi pada pengemudi taksi PT. Citra Perdana Kendedes Malang). Jurnal Administrasi Bisnis (JAB), 73(1), 225-232.

Indonesia, K. perindustrian. (2019). Lampaui 18 persen,industri tekstil dan pakaian tumbuh paling tinggi. Retrieved February 20, 2020, from www.kemenperin.go.id website: https://kemenperin.go.id/artikel/20666/lampaui-18-persen,-industri-tekstil-dan-pakaian-tumbuhpaling-tinggi

Jatiningrum, C. D., Musadieq, M. Al, \& Prasetya, A. (2016). Pengaruh budaya organisasi, motivasi dan kemampuan terhadap kinerja ( studi pada karyawan dan agen PT Asuransi Jiwasraya Branch Office Malang). Jurnal Administrasi Bisnis (JAB), 39(1), 117-124.

Livia Putri Kusuma, J. e. S. (2018). Peranan Kerjasama Tim Dan Semangat Kerja Terhadap Kinerja Karyawan Zolid Agung Perkasa. Jurnal Manajemen Dan Start-Up Bisnis, 3.

Mailisa, Y., Hendri, M. I., \& Fauzan, R. (2016). Pengaruh Iklim Organisasi dan Kemampuan Kerja Terhadap Komitmen Organisasional dan Dampaknya Pada Kinerja Pegawai DISPERINDAGKOP dan UKM Kota $\begin{array}{lllll}\text { Pontianak. Jurnal Ekonomi Bisnis Dan Kewirausahaan, } & 198 .\end{array}$ https://doi.org/10.26418/jebik.v5i3.19081

Muliadi. (2019). Peningkatan Produktivitas Kerja Karyawan Melalui Semangat Kerja (Suatu Penelitian pada Koperasi Warga Makmur Unit Marisa Kabupaten Pohuwato). 11(April), 87-104.

NA'IM, U. (2017). Pengaruh iklim organisasi, semangat kerja, dan kemampuan kerja terhadap kinerja pegawai kantor pelayanan pajak pratama kediri. Jurnal Revitalisasi Jurnal Ilmu Manajemen, 6. 
https://doi.org/10.1017/CB09781107415324.004

Nasution, D. A. D. (2019). Pengaruh Remunerasi Dan Semangat Kerja Terhadap Kinerja Pegawai Pada Kantor Kejaksaan Negeri Medan. JURNAL AKUNTANSI DAN BISNIS : Jurnal Program Studi Akuntansi, 5(1), 71. https://doi.org/10.31289/jab.v5i1.2441

Radot Rosana Devika.RG, R. S. (2019). Pengaruh Lingkungan Kerja Fisik dan Komunikasi Intern Terhadap Semangat Kerja Pegawai di Dinas Pendidikan Provinsi Sumatera Barat.2(September).

Riza, A. (2017). Pengaruh Kemampuan, Motivasi..., Moch Riza Afgani, Fakultas Ekonomi Dan Bisnis UMP. 9-45. sedarmayanti. (2017). Perencanaan dan pengembangan sdm untuk meningkatkan kompetensi kinerja dan produktivias kerja. In Manajemen sumber daya manusia bidang pendidikan. BANDUNG: pt.Refika aditama.

Sugara, F., Adji, S., \& Chamidah, S. (2020). Pengaruh komunikasi, motivasi, dan lingkungan kerja fisik terhadap semangat kerja karyawan Ud. Sukri Dana Abadi Ponorogo. ISOQUANT : Jurnal Ekonomi, Manajemen Dan Akuntansi, 4(1), 47. https://doi.org/10.24269/iso.v4i1.414 